\title{
Regression Models for 2-Dimensional Cartesian Coordinates Prediction: A Case study at University of Mines and Technology (UMaT), Tarkwa-Ghana.
}

\author{
Yao Yevenyo Ziggah ${ }^{1}$, Hu Youjian ${ }^{1}$, Christian Odutola Amans ${ }^{1}$, Bernard Kumi- \\ Boateng $^{2}$ \\ ${ }^{1}$ Department of Geodesy and Survey Engineering, China University of Geosciences, \\ Wuhan-P.R.China. \\ Ziggah781@hotmail.com; hyj_060163.com; christianodutolaleyahoo.com; \\ ${ }^{2}$ Department of Geomatic Engineering, University of Mines and Technology, Ghana. \\ kumi@umat.edu.gh
}

\begin{abstract}
The aim of this research is to study and analyze statistical models applicable in bringing out a relationship between global coordinates and cartesian planimetric coordinates of some known control stations in the University of Mines and Technology (UMaT) campus. To achieve the aims of this research, the Global Position System (GPS) latitudes and longitudes of selected control stations with known cartesian planimetric coordinates were determined using the Handheld GPS receiver at different epoch (morning and evening). Linear Regression analysis was then conducted to establish the correlation between global and cartesian planimetric coordinates of the selected control stations and regression models generated to show the results. The correlation coefficient $r$, a t-test for non-zero slope, $t$-test on correlation coefficient, graphical residual analysis, test of normality, comparing model predictions to observed data, were used to evaluate and check the adequacy of the models. The obtained results indicated that the proposed linear regression models are suitable for predictions at $95 \%$ confidence interval and do not violate any of the statistical assumptions of a linear model. However, the proposed regression models for the evening observation gave better prediction accuracy than the morning. A computer programming algorithm and a designed interface was created for the proposed regression models established using Microsoft C++ standard edition 6.0, thus making it easier in applying the models in making cartesian planimetric coordinates prediction at different epoch at UMaT.
\end{abstract}

\section{Keywords}

Global Coordinates, Cartesian Planimetric Coordinates, Global Position System (GPS)

\section{INTRODUCTION}

In the broad spectrum of activities covered by geodesy, one of the primary tasks is the establishment of a well defined coordinate system and datum for accurate positioning on the earth surface. These coordinate systems or datum's, which may be of a local or regional nature, or even of global extent, have a variety of uses in the realms of both scientific and applied geodesy. Many coordinate systems are available in geodesy and mapping. The most commonly 
used are the cartesian and global coordinate systems because the latitude/longitude concept will always have the most direct appeal for terrestrial applications like surveying, near-surface navigation, positioning and mapping [1]. For instance, the well-known Global Positioning System (GPS) receiver obtains global coordinates (latitude, longitude) which can be conveniently transformed into cartesian (Earth-Centre Earth-fixed) coordinate system for mapping surveys. Several transformation procedures and relationships have been put forth by researchers in transforming global coordinates to cartesian coordinates and vice versa $[2][3][4][5][6][7][8][9]$. The most widely used relationship between global coordinates (latitude, longitude, height) and cartesian coordinates (X, Y, Z) is given by Bowring's Algorithm [10][11][12][13][14][15][16]. Despite Bowring's algorithm establishing a mathematical relationship between global and cartesian coordinates and being widely used, the simplicity of this relationship is yet to be realized, especially in developing countries where geodesy has not reached advance stage. For example, in Ghana, before the formula can be used, the iterative Abridged Molodensky transformation is applied to the geographic coordinates of common points on the WGS 84 and Ghana War office ellipsoid to determine the transformation parameters which are in return used to calculate the ellipsoidal height. Instead of using these complex mathematical relations resulting in time consuming, it is proposed that linear regression model can serve as an alternative in predicting cartesian planimetric (2-D) coordinates and provides statistical meaning between the global and cartesian coordinates systems.

To this end, this research is aimed at determining regression models that can predict cartesian planimetric coordinates (X and Y) from global coordinates (Latitude and Longitude) at different epochs (morning and evening).

\section{MATERIALS AND METHODS}

\subsection{Presentation of the Study Area}

The University of Mines and Technology (UMaT) campus is the study area. UMaT is located in the mining town of Tarkwa in the Western Region of Ghana. Tarkwa is the Administrative capital of the Wassa West District located in the southwest of Ghana (approximately on longitude $2^{0} 59^{\prime} 45^{\prime \prime} \mathrm{W}$ and latitude $5^{0} 17^{\prime} 42^{\prime \prime} \mathrm{N}$ ) and is $160 \mathrm{~m}$ above mean sea level [17]. The town is about $85 \mathrm{~km}$ from Takoradi, which is the regional capital, $233 \mathrm{~km}$ from Kumasi and about $317 \mathrm{~km}$ from Accra [18][19]. The University Campus covers an area of approximately $1.39 \mathrm{~km}^{2}$ of undulating land and attractive surroundings, about $2 \mathrm{~km}$ south of Tarkwa [19]. Figure 1 is the map of Wassa West District showing location of Tarkwa. UMaT, Tarkwa area has a South-Western Equatorial Climate with seasons influenced by the moist South-West Monsoon Winds from the South Atlantic Ocean and the North-East Trade Winds. The mean rainfall is approximately $1500 \mathrm{~mm}$ with peaks of more than $1700 \mathrm{~mm}$ in June and October. Between November and February, the rainfall pattern decreases to between 20 and $90 \mathrm{~mm}$. The mean annual temperature is approximately 25 degrees Celsius with small daily temperature variations. Relative humidity varies from $61 \%$ in January to a maximum of $80 \%$ in August and September [20]. The topography of the Tarkwa area is generally described as a remarkable series of ridges and valleys parallel to one another and a true reflection of the pitching fold structures of the Banket Series of the Tarkwaian System. The ridges are formed by the Banket and Tarkwa phyllite whereas Upper quartzite and Huni Sandstone are present in the valleys. Surface gradients of the ridges are generally very close to the Banket and Tarkwa phyllite [17]. 


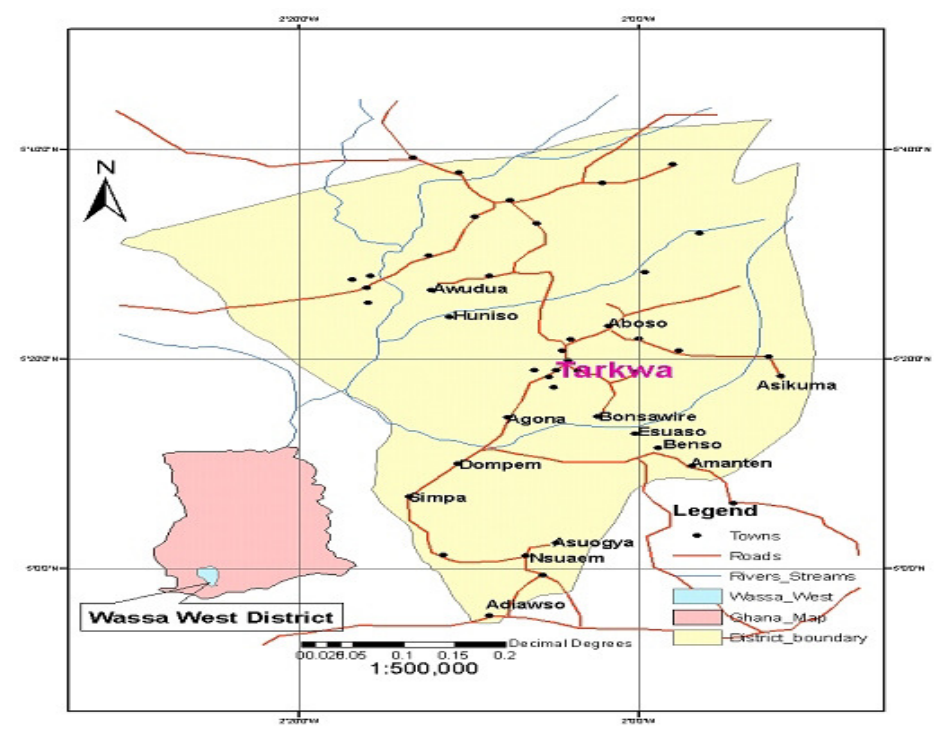

Figure 1. Map of Wassa West District showing Tarkwa [19]

\subsection{Materials}

Primary data was collected by field work using Handheld Global Positioning System (GPS) receiver. Data structures, descriptive and summary statistics for the various control stations selected were produced with International Business Machines Statistical Package for the Social Sciences Version 19 (IBM SPSS V.19). Maps were produced with ILWIS (Version 3.3).

\subsection{Methods}

The research work was carried out in the following steps: planning of the survey; reconnaissance; method of surveying and data acquisition; data processing and analysis.

\subsubsection{Planning of the Survey}

To ensure that results from GPS receivers are reliable and accurate there is a need for proper planning. During planning, several factors were considered as suggested by many researchers [21][19][22].

\subsubsection{Reconnaissance}

A reconnaissance survey was carried out at the UMaT campus. Fifteen (15) control points were selected for this research. Precautionary measures were taken into consideration in selecting the control points [19] because they must be reliable and suitable for GPS observations. The reconnaissance survey was carried out in a day. All potential problems to GPS survey work were taken note of. Through this exercise the boundary points of the survey area were picked as shown in Figure 2. 
International Journal of Computer Science \& Engineering Survey (IJCSES) Vol.3, No.6, December 2012

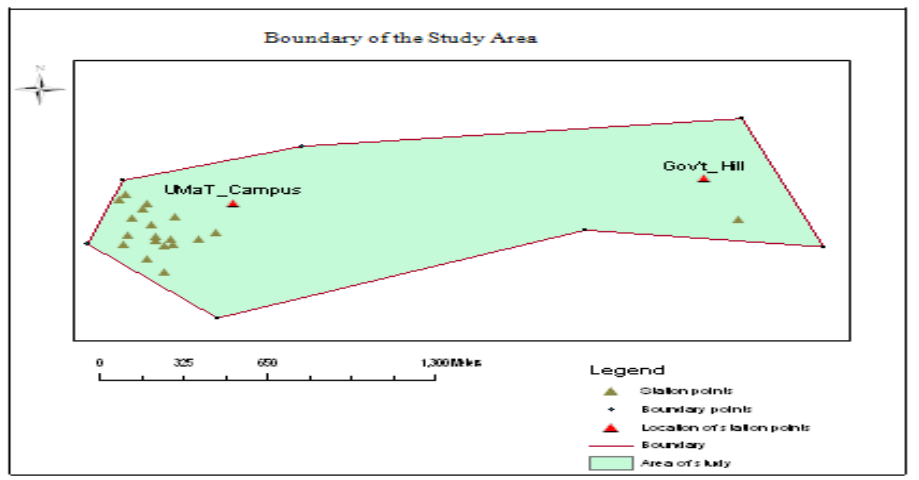

Figure 2. A Map showing boundary of the study area and station points

\subsubsection{Method of Surveying and Data Acquisition}

The absolute GPS Survey technique was adopted. In this research, a handheld GPS receiver was used to find the absolute positions (Latitude and Longitude) of the selected control points of known cartesian planimetric coordinates at UMaT. The static mode was used to operate the handheld GPS receiver. The observations were made in the morning and evening for a period of 3 days. In total, 45 datasets were collected. Data uploaded in the field by the receiver and recorded in the field book were sent to the office for post-processing.

\subsubsection{Data Processing and Analysis}

A sample of the downloaded raw data in degree decimals are shown in Table 1. The first and second day datasets (30 in total) were used to develop the regression model while the third day datasets (15 in total) were kept for validation purposes. Hence, the mean average of datasets applied for the model formulation was calculated as shown in Table 2. The IBM SPSS V.19 software was used to get the descriptive statistics for the research data.

Table 1. Raw data sample for both observations

\begin{tabular}{|c|c|c|c|c|c|c|c|}
\hline \multicolumn{3}{|c|}{ Control Points } & $\begin{array}{c}\text { TSM } \\
89 / 1 A\end{array}$ & $\begin{array}{c}\text { DMP } \\
\text { 2007/11 }\end{array}$ & TSM 1/98 & TSM 89/8 & FO1 \\
\hline \multirow{6}{*}{ 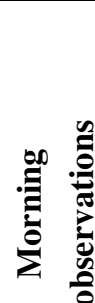 } & \multirow{2}{*}{$1^{\text {st }}$ Day } & Latitude & 0517.833 & 0517.880 & 0517.876 & 0517.886 & 0517.893 \\
\hline & & Longitude & 0200.065 & 0200.060 & 0200.036 & 0200.031 & 0159.984 \\
\hline & \multirow{2}{*}{$2^{\text {nd }}$ Day } & Latitude & 0517.878 & 0517.879 & 0517.870 & 0517.884 & 0517.884 \\
\hline & & Longitude & 0200.067 & 0200.064 & 0200.038 & 0200.035 & 0159.987 \\
\hline & \multirow{2}{*}{$3^{\text {rd Day }}$} & Latitude & 0517.878 & 0517.880 & 0517.874 & 0517.886 & 0517.890 \\
\hline & & Longitude & 0200.065 & 0200.062 & 0200.032 & 0200.035 & 0159.984 \\
\hline \multirow{6}{*}{ 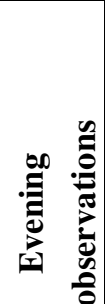 } & \multirow{2}{*}{$1^{\text {st }}$ Day } & Latitude & 0517.887 & 0517.879 & 0517.876 & 0517.886 & 0517.890 \\
\hline & & Longitude & 0200.064 & 0200.062 & 0200.035 & 0200.034 & 0159.987 \\
\hline & \multirow{2}{*}{$2^{\text {nd }}$ Day } & Latitude & 0517.890 & 0517.881 & 0517.876 & 0517.890 & 0517.889 \\
\hline & & Longitude & 0200.063 & 0200.063 & 0200.036 & 0200.035 & 0159.987 \\
\hline & \multirow{2}{*}{$3^{\text {rd Day }}$} & Latitude & 0517.885 & 0517.880 & 0517.875 & 0517.887 & 0517.890 \\
\hline & & Longitude & 0200.065 & 0200.061 & 0200.034 & 0200.033 & 0159.984 \\
\hline
\end{tabular}




\section{RESULTS AND DISCUSSIONS}

\subsection{Latitude and Longitude of Selected Control Stations}

It was observed from the raw data that, the latitudinal readings for only TSM 4/98 were in the range between $05^{0} 18.007^{\prime}$ to $05^{0} 18.009^{\prime}$. The rest of the data were between $05^{0} 17.833^{\prime}$ to $05^{0}$ $17.998^{\prime}$ for both morning and evening observations. The longitudinal readings observed for the stations were in the range from $02^{0} 00.011^{\prime}$ to $02^{0} 00.265^{\prime}$ but changes for the stations FO1, TSM $89 / 9$, TSM 4/98, and TSM 89/4 which lies between $01^{\circ} 59.966^{\prime}$ to $01^{\circ} 59.992^{\prime}$. To evaluate the datasets, the statistical mean for morning and evening observations were calculated for both latitude and longitude for all the fifteen selected control stations. Table 2 shows a section of the mean values of some selected control points for morning observation.

Table 2. A Sample of Mean values for morning observations

\begin{tabular}{|c|c|c|}
\hline Station & Mean Latitude & Mean Longitude \\
\hline TSM 89/1A & 5.297591667 & 2.001100000 \\
\hline DMP 2007/11 & 5.297991667 & 2.001033333 \\
\hline TSM 1/98 & 5.297883333 & 2.000616667 \\
\hline TSM 89/8 & 5.298083333 & 2.000550000 \\
\hline FO 1 & 5.298141667 & 1.999758333 \\
\hline
\end{tabular}

The change in the latitudinal readings for only TSM 4/98 and the longitudinal readings observed for the stations FO1, TSM 89/9, TSM 4/98, and TSM 89/4 are due to the fact that there was a certain drift in a particular direction from the central points of measurement more than the other stations. The positions of the stations are influenced by the direction of movement from the central points. With reference to Figure 3, points A and B are on the same Eastern but due to their positions the Northern values differ. The same applies to points $\mathrm{C}$ and $\mathrm{D}$. This shows that, at that particular control station there was a change in direction from the central readings.

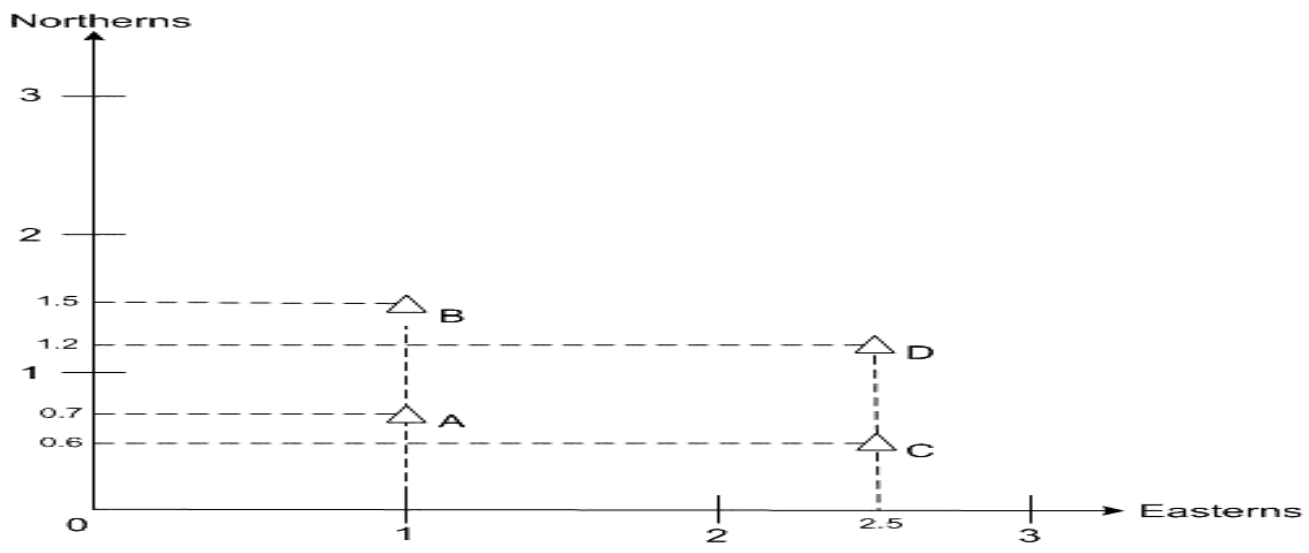

Figure 3. Shows the Influence of Positions on the Readings 


\subsection{Regression Models Developed}

Regression models were established between global (Latitude, Longitude) and cartesian planimetric coordinate $(\mathrm{X}, \mathrm{Y})$ systems as shown in Table 3 and Table 4 respectively. The regression model is in the form $Y_{i}=\beta_{0}+\beta_{1} X_{i}$. Where $Y_{i}$ is the estimated coordinates $(X / Y)$ in meters, $X_{\mathrm{i}}$ is the latitude/Longitude for both observations (morning and evening), $\beta_{0}$ is a constant, and $\beta_{1}$ is the regression model coefficient (slope).

Table 3. Regression Models for Morning Observations

\begin{tabular}{|c|c|}
\hline Graph & Regression Model \\
\hline $\begin{array}{c}\text { X-Coordinate against } \\
\text { longitude }\end{array}$ & X-Cord=-34459.862(longitude) +232301.356 \\
\hline Y-Coordinate against latitude & Y-Cord=103714.552 (latitude) -479895.291 \\
\hline
\end{tabular}

Table 4 . Regression Models for Evening Observation

\begin{tabular}{|c|c|}
\hline Graph & Regression Model \\
\hline $\begin{array}{c}\text { X-Coordinate against } \\
\text { longitude }\end{array}$ & X-Cord $=-107689.093$ (longitude) +378834.118 \\
\hline Y-Coordinate against latitude & Y-Cord $=109521.884$ (latitude) -510673.381 \\
\hline
\end{tabular}

The graphs in Figure 4(b) and 5(b) suggest a linear and negative slope between longitude and $X$ coordinate. The regression models (Table 3 and 4) for the $X$ coordinate also reveals that a negative slope exists between the variables (Longitude and $\mathrm{X}$ coordinate) such that for every one unit increase (decrease) in longitude, the $\mathrm{X}$ coordinate will decrease (increase) by 34459.862 and 107689.093 respectively. The existence of this negative relationship (slope) between the two variables is due to the fact that both variables are moving in opposite directions. Figure 4(a) and Figure 5(a), shows a linear and positive relationship (slope) between latitude and Y coordinates. The regression models for the $\mathrm{Y}$ coordinate in Table 3 and 4 also show a positive linear relationship (slope) because the latitude and $\mathrm{Y}$ coordinates move in the same direction such that as the latitude increases (decreases), $\mathrm{Y}$ increases (decreases) by 10371.4552 and 109521.884 respectively.

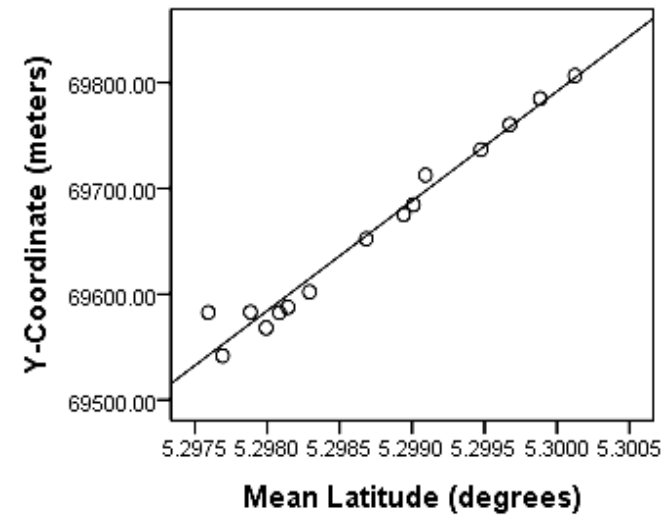

(a). A graph of $Y$-coordinate against Latitude

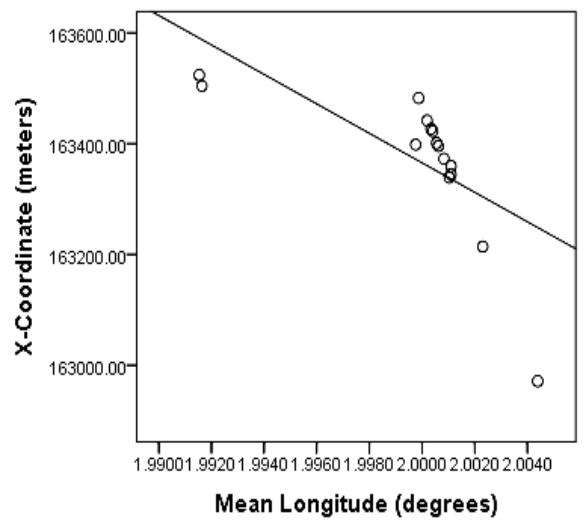

(b). A graph of $X$-coordinate against

Longitude 
Figure 4. Plotted Data for Morning Observations

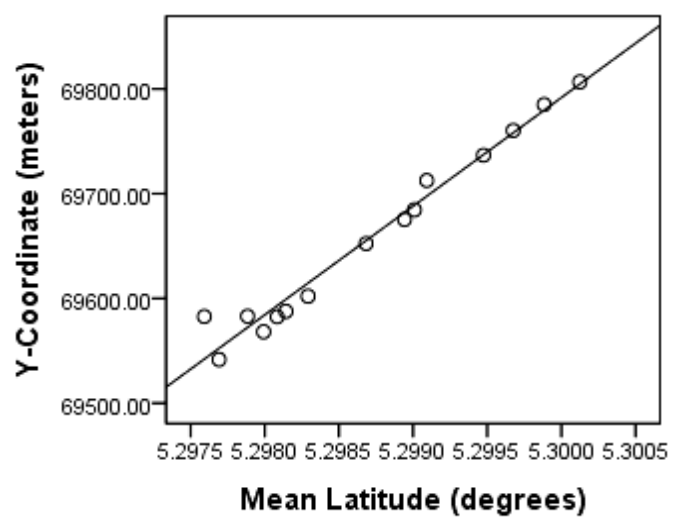

(a). A graph of $Y$-coordinate against Latitude

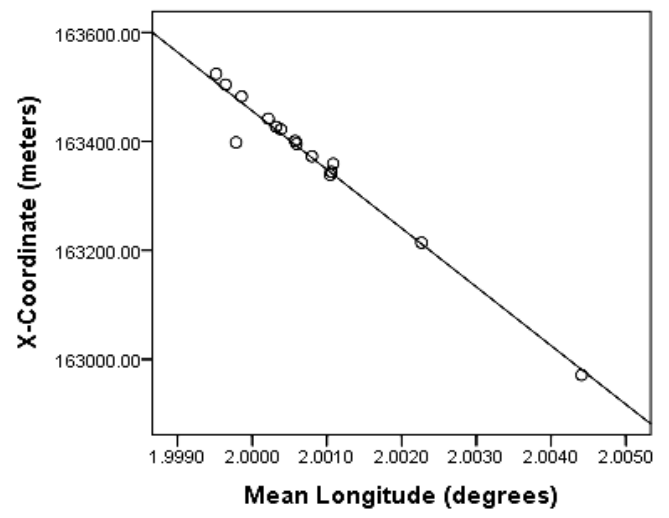

(b). A graph of X-coordinate against Longitude

Figure 5. Plotted Data for Evening Observations

\subsection{Checking the adequacy of the Regression Models developed}

The following methods elaborated below were the techniques used in the evaluation of the regression models determined between the global and cartesian planimetric coordinates system.

\subsection{1. $\mathbf{R}^{2}$ and $\mathbf{R}$ Statistic}

The deterministic model $\left(\mathrm{R}^{2}\right)$ and the correlation coefficients $(\mathrm{R})$ between the variables were calculated and the results are shown in Table $(5 \& 6)$. The coefficient of determination $\left(\mathrm{R}^{2}\right)$ is a criterion that is commonly used to measure the adequacy of the statistical prediction. The closer $\mathrm{R}^{2}$ is to 1 the better the prediction. On the basis of the results, the $\mathrm{R}^{2}$ values for longitudes were 0.476 and 0.969 for morning and evening observations, respectively (see table 5) while the latitude yielded 0.973 and 0.993 for morning and evening observations, respectively. These values of $\mathrm{R}^{2}$ indicated that the model describe the variation in the data with reliable accuracy except for longitude parameter when using morning observation data. The coefficient of correlation (r) corroborated this high strength of linear dependence between the two variables of the proposed regression models. In addition, comparison was made with respect to the correlation coefficient values obtained (Table 6). The results revealed a positive correlation between global and cartesian planimetric coordinates system for all the observations. The strength of the relationship for evening observations was stronger than that of the morning. This implies that a stronger relationship exist between the evening observations than morning observations. The correlation coefficient values obtained therefore, buttresses the point that GPS data should preferably be collected at night than during day time in absolute point positioning. This is because ionosphere is activated by solar radiation so its disturbances are much more severe on GPS observation during the day time than at night. 
International Journal of Computer Science \& Engineering Survey (IJCSES) Vol.3, No.6, December 2012

Table 5. Coefficient of Determination $\left(\mathbf{R}^{2}\right)$ for the Observations

\begin{tabular}{|c|c|c|c|}
\hline \multicolumn{2}{|c|}{ Morning } & \multicolumn{2}{c|}{ Evening } \\
\hline $\begin{array}{c}\text { Y-coordinate vs. } \\
\text { latitude }\end{array}$ & $\begin{array}{c}\text { X-coordinate vs. } \\
\text { longitude }\end{array}$ & $\begin{array}{c}\text { Y-coordinate vs. } \\
\text { latitude }\end{array}$ & $\begin{array}{c}\text { X-coordinate vs. } \\
\text { longitude }\end{array}$ \\
\hline 0.973 & 0.476 & 0.993 & 0.969 \\
\hline
\end{tabular}

Table 6. Correlation Coefficient ( $\mathbf{R})$ for the Observations

\begin{tabular}{|c|c|c|c|}
\hline \multicolumn{2}{|c|}{ Morning } & \multicolumn{2}{c|}{ Evening } \\
\hline $\begin{array}{c}\text { Y-coordinate vs. } \\
\text { latitude }\end{array}$ & $\begin{array}{c}\text { X-coordinate vs. } \\
\text { longitude }\end{array}$ & $\begin{array}{c}\text { Y-coordinate vs. } \\
\text { latitude }\end{array}$ & $\begin{array}{c}\text { X-coordinate vs. } \\
\text { longitude }\end{array}$ \\
\hline 0.986 & 0.690 & 0.996 & 0.984 \\
\hline
\end{tabular}

\subsubsection{Test for Non-Zero Slope}

A hypotheses test for regression model coefficient (slope) was performed at 5\% significance. This was done to ascertain whether the true value of the regression model coefficient, the slope $\left(\beta_{1}\right)$, has a significant linear relationship between Latitude/Longitude and $\mathrm{X} / \mathrm{Y}$ coordinates. If there is, then the slope will be significantly different from zero. Table 7 shows the calculated I $\mathbf{t} \mid$ (non-zero slope) for both morning and evening observations. In order to test these hypotheses, the measures of dispersion (standard error) around the slope estimate were calculated (Table 8). An interval was also constructed around the slope estimates and a two tailed test of $95 \%$ Confidence Interval was performed as shown in Table 9.

Testing of Hypothesis: $\mathrm{H}_{0}: \beta_{1}=0$ (Slope is equal to zero)

Significance Level: $\quad \alpha=0.05$

$$
\mathrm{H}_{1}: \beta_{1} \neq 0 \text { (Slope is not equal to zero) }
$$

Test Statistic: $t=\frac{b_{1}}{S_{1}}$ where $S_{1}$ estimates the variance of the estimated slope $b_{1}$ for the research data.

Decision Rule: Reject $\mathrm{H}_{0}$ if $|\mathrm{t}|>\mathrm{t}_{\alpha / 2, \mathrm{n}-2}$; from student $\mathrm{t}$-distribution tables, $\mathrm{t}_{(0.025,13)}=2.16037$ Conclusion: If the calculated $I \mathrm{t} I$ is greater than $\mathrm{t}_{\alpha / 2, \mathrm{n}-2}$, reject the null hypothesis and vice versa. 95\% Confidence Interval for $\boldsymbol{\beta}_{\mathbf{1}}$ :

$$
b_{1}-t_{(0.025,13)} \times S_{1}<\beta_{1}<b_{1}+t_{(0.025,13)} \times S_{1}
$$

Table 7: Calculated I $\mathrm{t}$ for non-zero slope

\begin{tabular}{|c|c|c|c|}
\hline \multicolumn{2}{|c|}{ Morning } & \multicolumn{2}{c|}{ Evening } \\
\hline $\begin{array}{c}\text { Y-coordinate } \\
\text { vs. latitude }\end{array}$ & X-coordinate vs. longitude & $\begin{array}{c}\text { Y-coordinate vs. } \\
\text { latitude }\end{array}$ & $\begin{array}{c}\text { X-coordinate vs. } \\
\text { longitude }\end{array}$ \\
\hline 21.632 & 3.440 & 41.901 & 20.203 \\
\hline
\end{tabular}

Table 8: Standard Error for the slope estimates $\left(\mathrm{S}_{1}\right)$

\begin{tabular}{|c|c|c|c|}
\hline \multicolumn{2}{|c|}{ Morning } & \multicolumn{2}{c|}{ Evening } \\
\hline $\begin{array}{c}\text { Y-coordinate } \\
\text { vs. latitude }\end{array}$ & X-coordinate vs. longitude & $\begin{array}{c}\text { Y-coordinate vs. } \\
\text { latitude }\end{array}$ & $\begin{array}{c}\text { X-coordinate vs. } \\
\text { longitude }\end{array}$ \\
\hline 4794.461 & 7730.692 & 2613.852 & 5330.239 \\
\hline
\end{tabular}


Table 9: Confidence Interval for the slope (Morning and Evening Observation)

\begin{tabular}{|c|c|}
\hline & Morning \\
\hline Y-coordinate vs. latitude & $X$-coordinate vs. longitude \\
\hline $93356.748<\beta_{1}<114072.356$ & $-56,237.884<\beta_{1}<-12681.841$ \\
\hline & Evening \\
\hline Y-coordinate vs. latitude & $X$-coordinate vs. longitude \\
\hline $103875.00<\beta_{1}<115168.768$ & $-119204.381<\beta_{1}<-96173.805$ \\
\hline
\end{tabular}

From table 7, since calculated I $\mathbf{t} I$ exceeds the appropriate critical values $t_{(0.025,13)}=2.16037$, the conclusion is that the data provides convincing evidence that $\beta_{1}$ is different from zero. This attest to the point that there is a non-zero (positive) association between global and cartesian planimetric coordinate system, hence $\mathrm{H}_{0}: \beta_{1}=0$ is rejected. A $95 \%$ confidence interval for the slope $\beta_{1}$ is shown in Table 9 . The probability is 0.95 that the values of the population slope, $\beta_{1}$ is between the individual intervals for the observations shown in Table 9. Since the value of zero does not fall within the interval the null hypothesis is rejected.

\subsection{3. t-test on the correlation coefficients}

To further confirm the correlation between global and cartesian planimetric coordinates for both morning and evening observations, a test of hypotheses (t statistic) was conducted on the correlation coefficients. The results established a strong correlation between the global and cartesian planimetric coordinates for morning and evening observations (Table 10). Since the calculated | t | (Table 10) is greater than the critical value $\mathrm{t}_{(0.025,13)}=2.16037$, hence the hypothesis of no correlation is rejected.

Testing of Hypothesis: All global coordinates do not have any correlation with the planimetric cartesian coordinates System.

Null hypothesis: $\quad \mathrm{H}_{0}: \rho=0$

Alternative Hypothesis: $\mathrm{H}_{1}: \rho \neq 0$

Significance Level: $\quad \alpha=0.05$

Test Statistic: $\quad t=r \frac{\sqrt{n-2}}{\sqrt{1-r^{2}}}$

Where; $r=$ correlation coefficient (refer to Table 5)

$\mathrm{n}=$ number of observations $=15$

Decision Rule: Reject $\mathrm{H}_{0}$ if $|\mathrm{t}|>\mathrm{t}_{\alpha / 2, \mathrm{n}-2}$; from student $\mathrm{t}$-distribution tables, $\mathrm{t}_{(0.025,13)}=2.16037$

Conclusion: If the calculated $|\mathrm{t}|$ is greater than $\mathrm{t}_{\alpha / 2, \mathrm{n}-2}$, reject the null hypothesis and vice versa.

Table 10: Calculated I $\mathrm{t}$ | for correlation coefficient

\begin{tabular}{|c|c|c|c|}
\hline \multicolumn{2}{|c|}{ Morning } & \multicolumn{2}{c|}{ Evening } \\
\hline $\begin{array}{c}\text { Y-coordinate } \\
\text { vs. latitude }\end{array}$ & X-coordinate vs. longitude & $\begin{array}{c}\text { Y-coordinate vs. } \\
\text { latitude }\end{array}$ & $\begin{array}{c}\text { X-coordinate vs. } \\
\text { longitude }\end{array}$ \\
\hline 21.629 & 3.4182 & 41.785 & 20.165 \\
\hline
\end{tabular}




\subsubsection{Assessing the sufficiency of the Functional Part of the Model}

To assess the sufficiency of the functional part of the model, scatter plots of the residuals against the independent variables in the model was done. The residual plots for morning and evening observations do not exhibit any systematic structure indicating that the model fit the data well as shown in Figure $6 \& 7$ for both morning and evening observations.

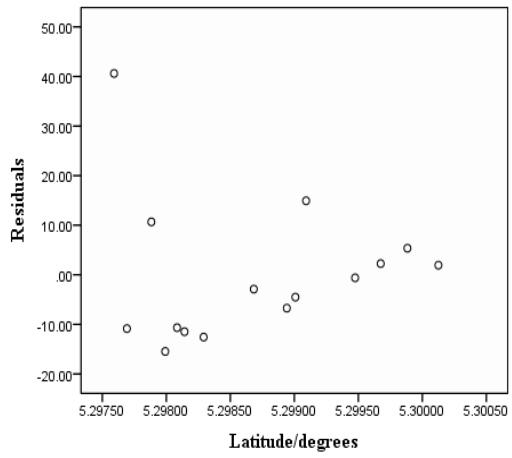

(a). Latitude

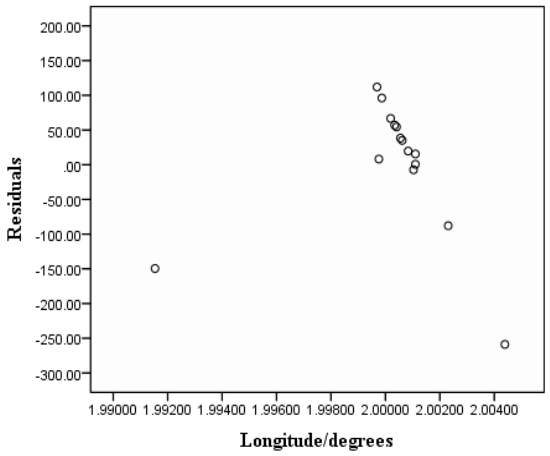

(b). Longitude

Figure 6. Plot of Residuals against Independent Morning Observations

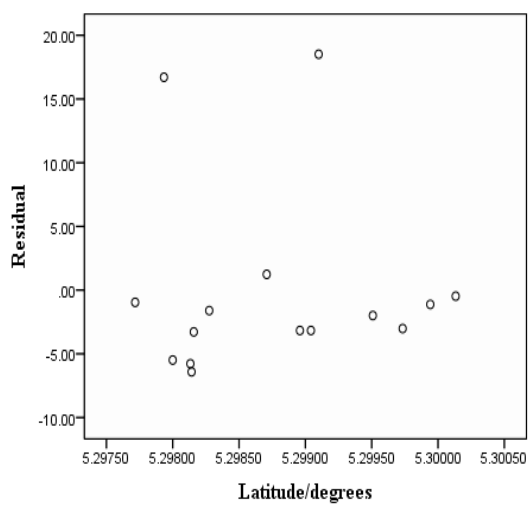

(a). Latitude

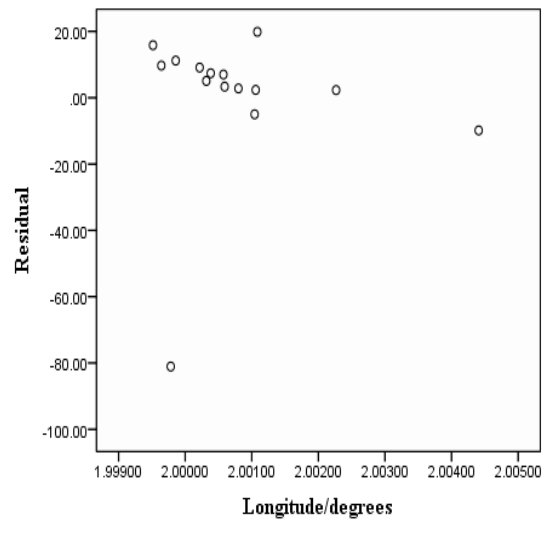

(b). Longitude

Figure 7. Plot of Residuals against Independent Evening Observations

It can be observed in Figure $6 \& 7$ that the residuals are randomly distributed around the horizontal line representing a residual error of zero. That is, there is no distinct trend in the distribution of the points. The residual plots for morning and evening observations do not exhibit any systematic structure suggesting that the model fit the data well and the statistical assumption that regression function is linear in the parameters is fully satisfied as Figure $6 \& 7$ buttress this point.

\subsubsection{Detecting Non- Constant Variation across data}

A scatter plot of the residuals against the predicted values was carried out (Figure $8 \& 9$ ). This allows comparison of the amount of random variation in different parts of the data. The result 
shows that the residuals look essentially constant across the levels of the predictor variables (Latitude and Longitude) as demonstrated in Figure $8 \& 9$ for both epochs of observations respectively. No pattern in the residual data is apparent. This suggests that the standard deviation of the random errors is the same for the responses observed at each latitude or longitude. The problem of increasing variance of error terms that violates the assumption of equal variance does not exist in this case.

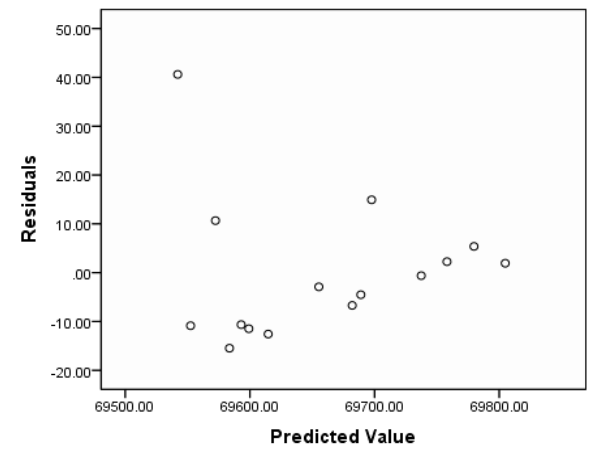

(a). Latitude

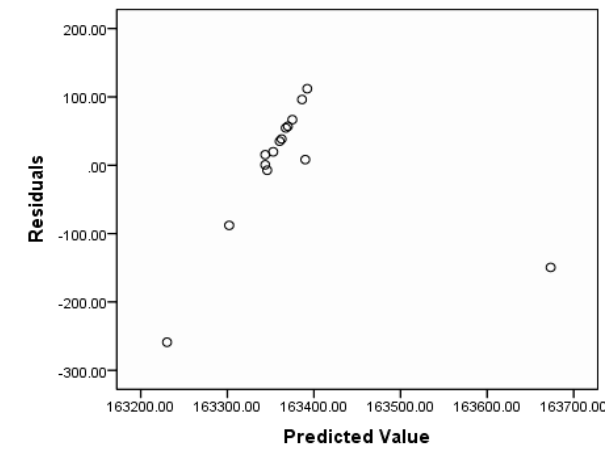

(b). Longitude

Figure 8. Plot of Residuals against Predicted values for Morning Observations

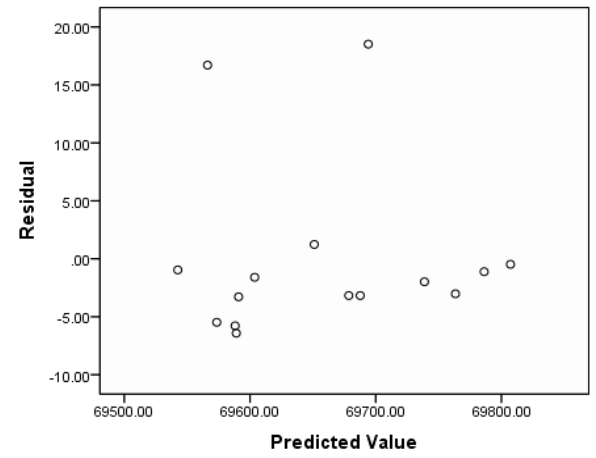

(a). Latitude

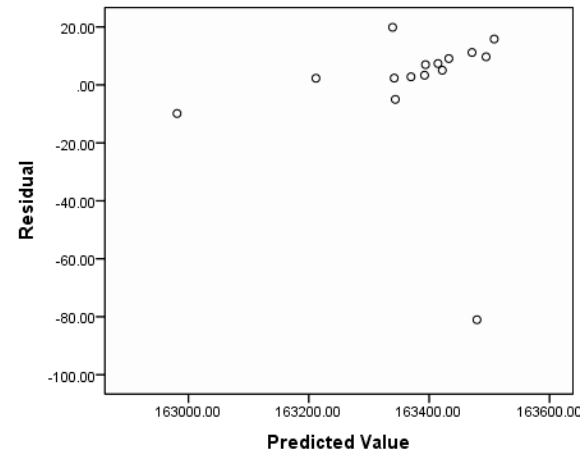

(b). Longitude

Figure 9. Plot of Residuals against Predicted values for Evening Observations

\subsubsection{Assessing the independency of the Random Errors}

The statistical assumption of independent random errors was tested using the lag plot of residuals for both observations. This was used to suggest whether an error term is independent or not. With reference to Figure $10 \& 11$, the lag residual plots suggest that the error terms from each fits are independent. There is no deterministic pattern or structure evident in the lag residual plots. In each case, the residuals are randomly scattered around the origin in a scattershot fashion. The same situation was observed for all observations. 
International Journal of Computer Science \& Engineering Survey (IJCSES) Vol.3, No.6, December 2012

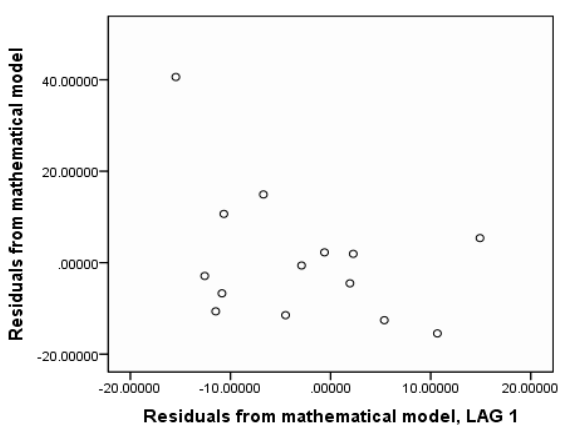

(a). Latitude

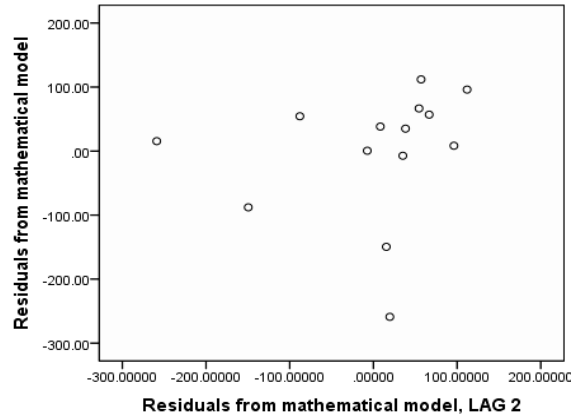

(b). Longitude

Figure 10. Lag Plot of Residuals for Morning Observations

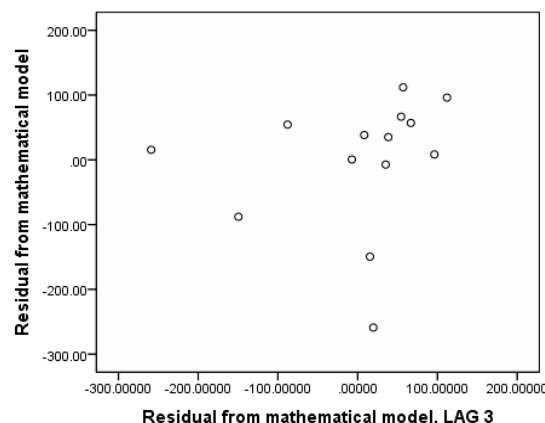

(a). Latitude

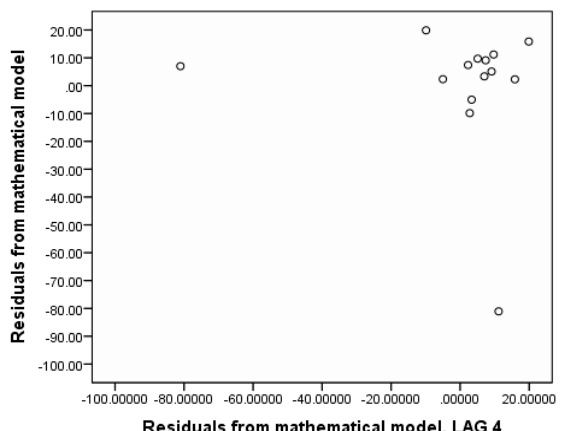

(b). Longitude

Figure 11. Lag Plot of Residuals for Evening Observations

\subsubsection{Testing Normality of Random Errors}

To further test and verify the normality assumptions of the random errors (error terms) in the model, the histogram of residuals and normality probability plot for all observations (morning and evening) was done. The results attest to it that the random errors in the models developed follows normal distribution (Figure 12-15). As shown in Figure 14\&15, the data are spread roughly along the straight line. This concludes that the data are normally distributed. The shape of the histogram (Figure $12 \& 13$ ) supports this conclusion.

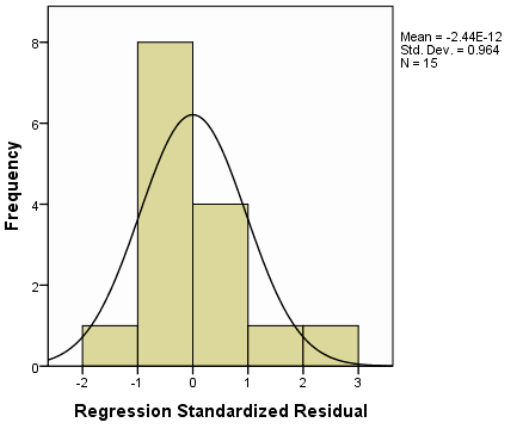

(a). Latitude

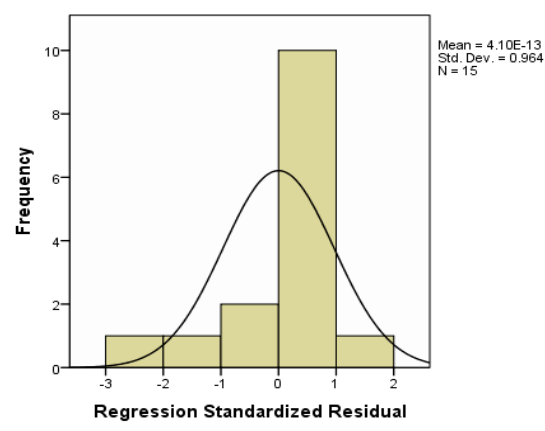

(b). Longitude

Figure 12. Histogram of Residuals Plot for Morning Observations 
International Journal of Computer Science \& Engineering Survey (IJCSES) Vol.3, No.6, December 2012

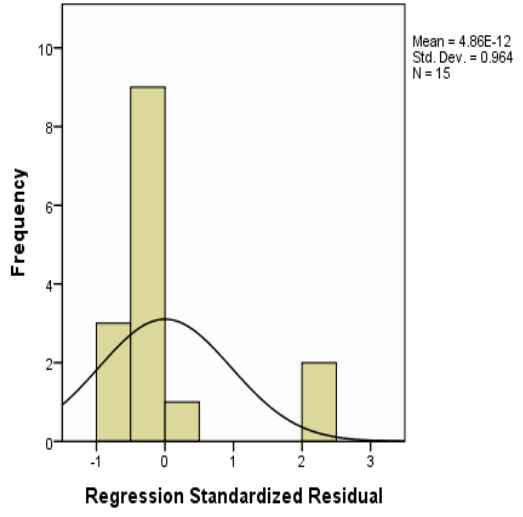

(a). Latitude

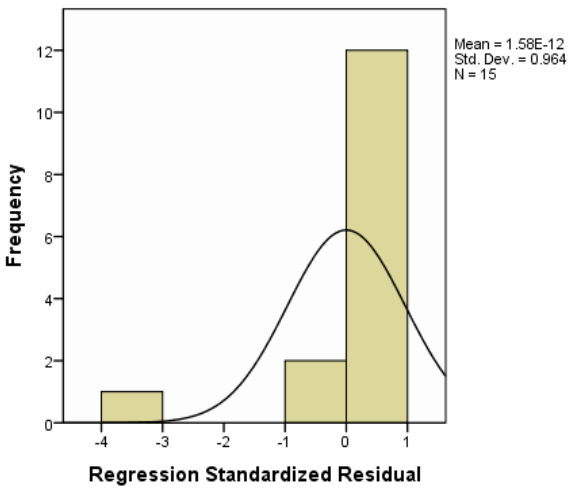

(b). Longitude

Figure 13. Histogram of Residuals Plot for Evening Observations

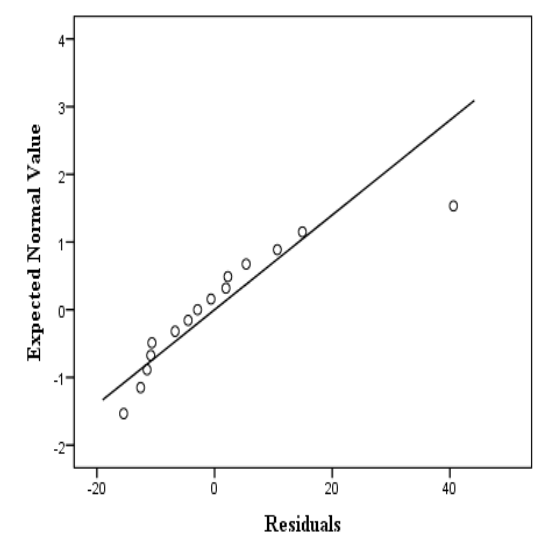

(a). Latitude

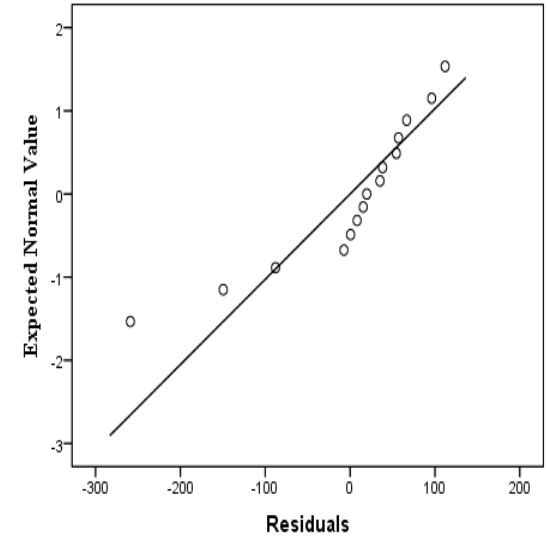

(b). Longitude

Figure 14. Normality Probability Plot of residuals for Morning Observations

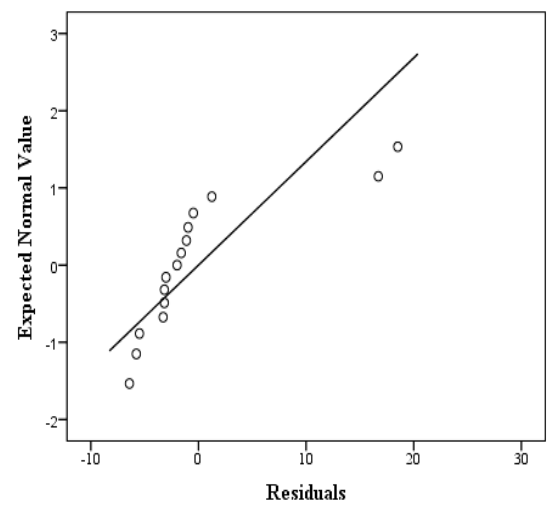

(a). Latitude

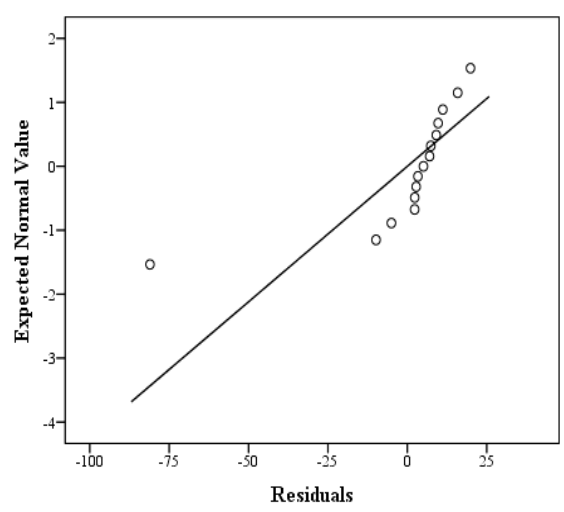

(b). Longitude

Figure 15. Normality Probability Plot of residuals corresponding to Evening Observations 


\subsubsection{Testing Model Validity}

The validity of the regression models was further tested by drawing scatter diagrams. Typical scatter diagrams for all models are presented in Figure16\&17. The figures represent scatter plots from the 15 independent validation data (data collected on the 3rd day of observation). Figure $16 \& 17$ were used to show the correlation between the residuals. It was noticed from the figures that there is an existence of over and under predictions by the regression models. The model prediction results for all observations (morning and evening) are shown in Table 11 and 12. In order to make the application of the models easier, an executable program was created for the developed regression models with the MFC AppWizard (exe) in project using Microsoft $\mathrm{C}++6.0$ standard edition. The idea in the computer programming algorithm and the designed interface for this research work will enhance easy prediction of cartesian planimetric coordinates in the UMaT campus. Figure 18 shows the designed interface when the MFC.exe application was executed. This interface can be used by inputting the latitude and longitude readings of any survey control in UMaT and clicking on the calculate bottom. This gives the cartesian planimetric coordinates in UMaT.
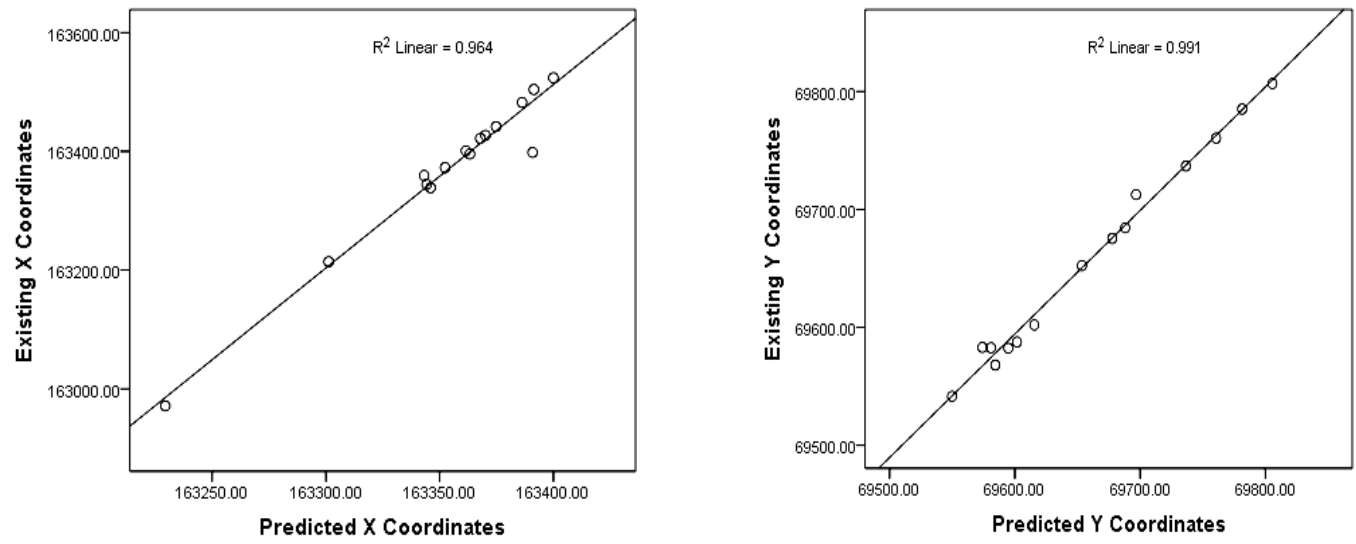

Figure 16. Scatter plot of Existing against Predicted coordinates for Morning Observations
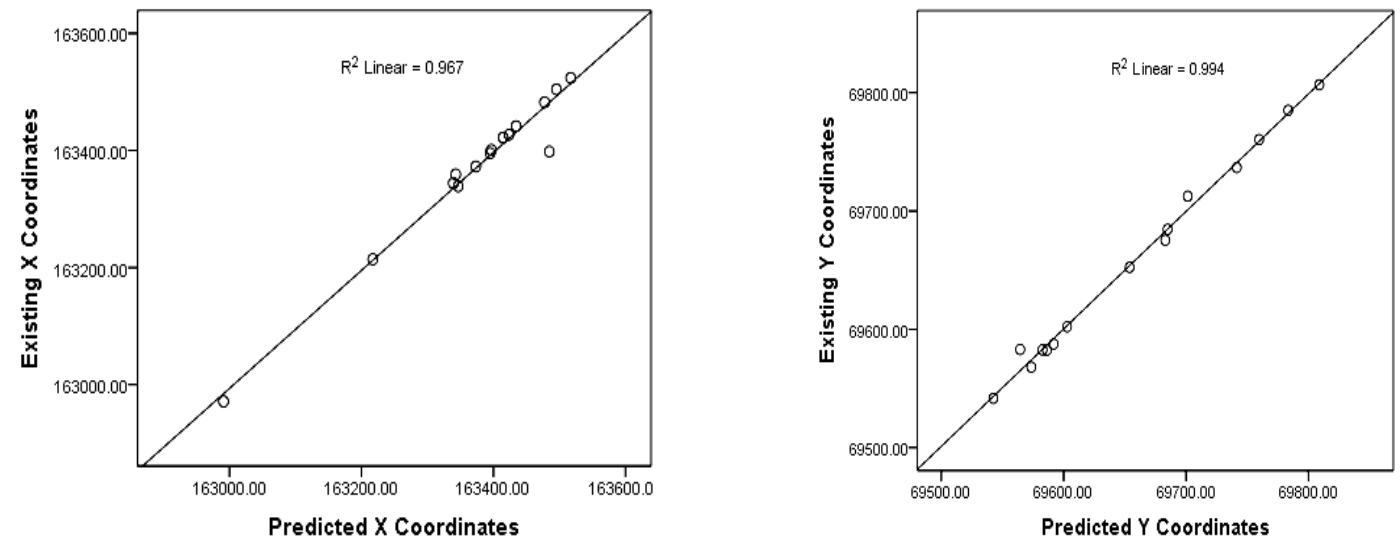

Figure 17. Scatter plot of Existing against Predicted coordinates for Evening Observations

The plot in Figure 16\&17, shows data points lying below and above the $Y=X$ line, indicate overand under-prediction by the regression models, respectively. It was also observed from Figure 
$16 \& 17$ that a tendency to have runs of positive and negative residuals indicates the existence of a certain correlation. The plot shows that the residuals are distributed evenly in both positive and negative along the run. Hence the data is independent. With reference to Figure 16\&17, the observed values and predicted values of the responses are scattered close to the $45^{\circ}$ line indicating an almost perfect fit of the developed regression model. It was also noted that the results obtained from the model proved that the error associated in the predictions (independent check) is much lower than the one obtained by the theoretical model predictions. This means that the regression model can predict to a higher accuracy as shown in Figure $16 \& 17$.

A critical observation of model prediction values (shown in Table $11 \& 12$ below) shows that the regression models for the evening observations have a higher predictable accuracy than the morning. This strongly suggests that the data collected with a GPS in the evening is better than in the morning. The negative and positive residual values in Table $11 \& 12$ represent under predictions and over predictions by the regression models. Finally, in both observations, the predicted values for $\mathrm{Y}$ coordinate were better than $\mathrm{X}$ coordinate.

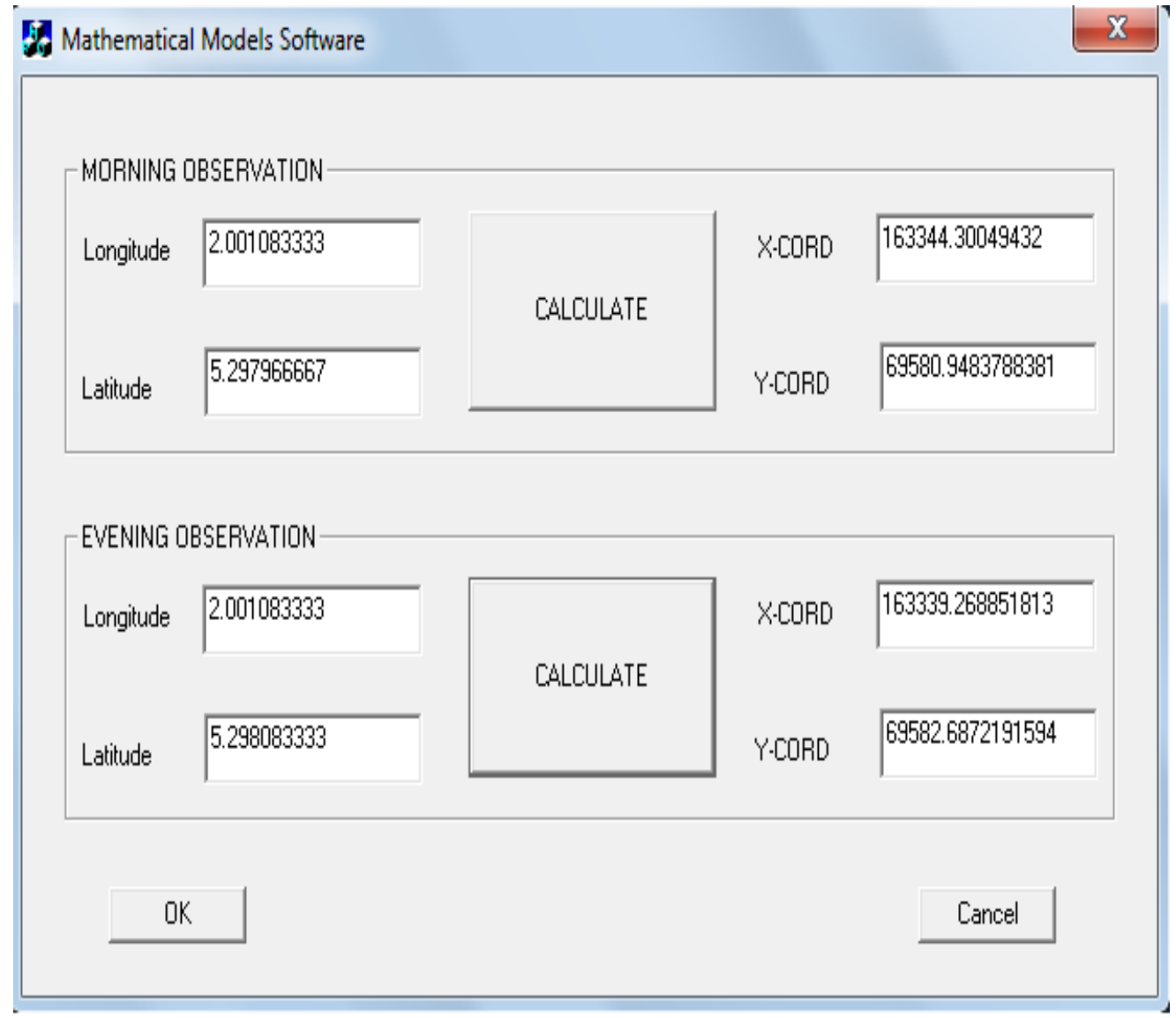

Figure 18. The designed interface 
International Journal of Computer Science \& Engineering Survey (IJCSES) Vol.3, No.6, December 2012

Table 11. Model predictions and residuals for Morning Observations

\begin{tabular}{|c|c|c|c|c|c|c|c|c|}
\hline \multirow[b]{2}{*}{$\begin{array}{l}\text { CONTRO } \\
\text { L POINT }\end{array}$} & \multicolumn{2}{|c|}{$\begin{array}{c}\text { EXISTING } \\
\text { COORDINATES } \\
\end{array}$} & \multicolumn{2}{|c|}{ DATA FOR TESTING } & \multicolumn{2}{|c|}{$\begin{array}{c}\text { PREDICTED } \\
\text { COORDINATES } \\
\end{array}$} & \multicolumn{2}{|c|}{ RESIDUALS } \\
\hline & $\begin{array}{l}\text { Eastings } \\
(\mathbf{X})\end{array}$ & $\begin{array}{c}\text { Northings } \\
(\mathbf{Y})\end{array}$ & Longitude & Latitude & $\begin{array}{l}\text { Eastings } \\
(\mathbf{X})\end{array}$ & $\begin{array}{l}\text { Northings } \\
\text { (Y) }\end{array}$ & $\begin{array}{l}\text { Eastings } \\
(\mathbf{X})\end{array}$ & $\begin{array}{c}\text { Northi } \\
\text { ngs } \\
(\mathbf{Y}) \\
\end{array}$ \\
\hline $\begin{array}{l}\text { TSM } \\
89 / 1 \mathrm{~A} \\
\end{array}$ & 163344.30 & 69582.66 & 2.001083333 & $\begin{array}{c}5.2979666 \\
67 \\
\end{array}$ & $\begin{array}{c}163344 . \\
30 \\
\end{array}$ & 69580.95 & -0.0005 & 1.7116 \\
\hline $\begin{array}{c}\text { DMP } \\
2007 / 11 \\
\end{array}$ & 163338.74 & 69568.08 & 2.001033333 & $\begin{array}{c}5.2980000 \\
00\end{array}$ & $\begin{array}{c}163346 . \\
02\end{array}$ & 69584.41 & -7.2835 & $\begin{array}{c}- \\
16.325 \\
5\end{array}$ \\
\hline TSM 1/98 & 163395.54 & 69582.97 & 2.000533333 & $\begin{array}{c}5.2979000 \\
00\end{array}$ & $\begin{array}{c}163363 . \\
25\end{array}$ & 69574.03 & 32.2866 & 8.9360 \\
\hline TSM $89 / 8$ & 163401.02 & 69582.39 & 2.000583333 & $\begin{array}{c}5.2981000 \\
00\end{array}$ & $\begin{array}{c}163361 . \\
53\end{array}$ & 69594.78 & 39.4896 & $\begin{array}{c}- \\
12.387 \\
0\end{array}$ \\
\hline FO 1 & 163398.22 & 69587.62 & 1.999733333 & $\begin{array}{c}5.2981666 \\
67\end{array}$ & $\begin{array}{c}163390 . \\
82\end{array}$ & 69601.69 & 7.3987 & $\begin{array}{c}- \\
14.071 \\
3 \\
\end{array}$ \\
\hline TSM 89/9 & 163482.36 & 69684.48 & 1.999866667 & $\begin{array}{c}5.2990000 \\
00\end{array}$ & $\begin{array}{c}163386 . \\
23\end{array}$ & 69688.12 & 96.1334 & $\begin{array}{c}- \\
3.6400\end{array}$ \\
\hline TSM 4/98 & 163504.22 & 69806.73 & 1.999716667 & $\begin{array}{c}5.3001333 \\
33\end{array}$ & $\begin{array}{c}163391 . \\
40\end{array}$ & 69805.66 & 112.8244 & 1.0668 \\
\hline TSM CT1 & 163426.90 & 69760.38 & 2.000333333 & $\begin{array}{c}5.2997000 \\
00\end{array}$ & $\begin{array}{c}163370 . \\
15\end{array}$ & 69760.72 & 56.7546 & $\begin{array}{c}- \\
0.3402 \\
\end{array}$ \\
\hline TSM 89/5 & 163441.71 & 69736.77 & 2.000200000 & $\begin{array}{c}5.2994666 \\
67 \\
\end{array}$ & $\begin{array}{c}163374 . \\
74\end{array}$ & 69736.52 & 66.9700 & 0.2498 \\
\hline TSM 89/6 & 163422.05 & 69652.38 & 2.000400000 & $\begin{array}{c}5.2986666 \\
67 \\
\end{array}$ & $\begin{array}{c}163367 . \\
85 \\
\end{array}$ & 69653.55 & 54.2019 & $\begin{array}{c}- \\
1.1686 \\
\end{array}$ \\
\hline $\begin{array}{l}\text { GCGWP } \\
10 / 50,10 \\
\end{array}$ & 163214.14 & 69602.08 & 2.002333333 & $\begin{array}{c}5.2983000 \\
00 \\
\end{array}$ & $\begin{array}{c}163301 . \\
23\end{array}$ & 69615.52 & -87.0857 & $\begin{array}{c}- \\
13.439 \\
9\end{array}$ \\
\hline TSM $89 / 4$ & 163523.83 & 69785.10 & 1.999466667 & $\begin{array}{c}5.2999000 \\
00\end{array}$ & $\begin{array}{c}163400 . \\
01\end{array}$ & 69781.46 & 123.8194 & 3.6369 \\
\hline $\begin{array}{l}\text { GCG } \\
15 \mathrm{E} / 35\end{array}$ & 163359.15 & 69712.55 & 2.001116667 & $\begin{array}{c}5.2990833 \\
33 \\
\end{array}$ & $\begin{array}{c}163343 . \\
15\end{array}$ & 69696.76 & 15.9982 & $\begin{array}{c}15.787 \\
1 \\
\end{array}$ \\
\hline $\begin{array}{l}\text { DMP } \\
2007 / 12\end{array}$ & 162971.34 & 69675.35 & 2.004416667 & $\begin{array}{c}5.2989000 \\
00\end{array}$ & $\begin{array}{c}163229 . \\
43\end{array}$ & 69677.75 & -258.0943 & $\begin{array}{c}- \\
2.3986 \\
\end{array}$ \\
\hline $\begin{array}{l}\text { WUC } \\
04 / 12\end{array}$ & 163372.56 & 69541.57 & 2.000850000 & $\begin{array}{c}5.2976666 \\
67\end{array}$ & $\begin{array}{c}163352 . \\
34\end{array}$ & 69549.83 & 20.2189 & $\begin{array}{c}- \\
8.2640\end{array}$ \\
\hline
\end{tabular}

Table 12. Model predictions and residuals for Evening Observations

\begin{tabular}{|c|c|c|c|c|c|c|c|c|}
\hline \multirow{2}{*}{$\begin{array}{l}\text { CONTR } \\
\text { OL } \\
\text { POINT }\end{array}$} & \multicolumn{2}{|c|}{$\begin{array}{c}\text { EXISTING } \\
\text { COORDINATES }\end{array}$} & \multicolumn{2}{|c|}{ DATA FOR TESTING } & \multicolumn{2}{|c|}{$\begin{array}{c}\text { PREDICTED } \\
\text { COORDINATES }\end{array}$} & \multicolumn{2}{|c|}{ RESIDUALS } \\
\hline & $\begin{array}{l}\text { Eastings } \\
(\mathbf{X})\end{array}$ & $\begin{array}{c}\text { Northing } \\
\text { s (Y) }\end{array}$ & Longitude & Latitude & $\begin{array}{l}\text { Eastings } \\
\text { (X) }\end{array}$ & $\begin{array}{l}\text { Northings } \\
\text { (Y) }\end{array}$ & $\begin{array}{l}\text { Eastings } \\
\text { (X) }\end{array}$ & $\begin{array}{l}\text { Northings } \\
\text { (Y) }\end{array}$ \\
\hline $\begin{array}{l}\text { TSM } \\
89 / 1 \mathrm{~A}\end{array}$ & $\begin{array}{c}163344 \\
30\end{array}$ & $\begin{array}{c}69582.6 \\
6\end{array}$ & $\begin{array}{c}2.00108333 \\
3\end{array}$ & $\begin{array}{c}5.2980833 \\
33\end{array}$ & $\begin{array}{c}163339.2 \\
7\end{array}$ & 69582.69 & 5.0311 & -0.0272 \\
\hline $\begin{array}{l}\text { DMP } \\
2007 / 11\end{array}$ & $\begin{array}{c}163338 . \\
74\end{array}$ & $\begin{array}{c}69568.0 \\
8\end{array}$ & $\begin{array}{c}2.00101666 \\
7\end{array}$ & $\begin{array}{c}5.2980000 \\
00\end{array}$ & $\begin{array}{c}163346.4 \\
5\end{array}$ & 69573.56 & -7.7081 & -5.4804 \\
\hline $\begin{array}{l}\text { TSM } \\
1 / 98\end{array}$ & $\begin{array}{c}163395 . \\
54\end{array}$ & $\begin{array}{c}69582.9 \\
7\end{array}$ & $\begin{array}{c}2.00056666 \\
7\end{array}$ & $\begin{array}{c}5.2979166 \\
67\end{array}$ & $\begin{array}{c}163394.9 \\
1\end{array}$ & 69564.43 & 0.6319 & 18.5364 \\
\hline $\begin{array}{l}\text { TSM } \\
89 / 8\end{array}$ & $\begin{array}{c}163401 . \\
02\end{array}$ & $\begin{array}{c}69582.3 \\
9\end{array}$ & $\begin{array}{c}2.00055000 \\
0\end{array}$ & $\begin{array}{c}5.2981166 \\
67\end{array}$ & $\begin{array}{c}163396.7 \\
0\end{array}$ & 69586.34 & 4.3170 & -3.9480 \\
\hline FO 1 & $\begin{array}{c}163398 . \\
22\end{array}$ & $\begin{array}{c}69587.6 \\
2\end{array}$ & $\begin{array}{c}1.99973333 \\
3\end{array}$ & $\begin{array}{c}5.2981666 \\
67\end{array}$ & $\begin{array}{c}163484.6 \\
5\end{array}$ & 69591.81 & -86.4291 & -4.1941 \\
\hline $\begin{array}{l}\text { TSM } \\
89 / 9\end{array}$ & $\begin{array}{c}163482 . \\
36\end{array}$ & $\begin{array}{c}69684.4 \\
8\end{array}$ & $\begin{array}{c}1.99980000 \\
0\end{array}$ & $\begin{array}{c}5.2990166 \\
67\end{array}$ & $\begin{array}{c}163477.4 \\
7\end{array}$ & 69684.91 & 4.8902 & -0.4277 \\
\hline $\begin{array}{l}\text { TSM } \\
4 / 98\end{array}$ & $\begin{array}{c}163504 . \\
22\end{array}$ & $\begin{array}{c}69806.7 \\
3\end{array}$ & $\begin{array}{c}1.99963333 \\
3\end{array}$ & $\begin{array}{c}5.3001500 \\
00\end{array}$ & $\begin{array}{c}163495.4 \\
2\end{array}$ & 69809.03 & 8.8020 & -2.3025 \\
\hline $\begin{array}{l}\text { TSM } \\
\text { CT1 }\end{array}$ & $\begin{array}{c}163426 . \\
90\end{array}$ & $\begin{array}{c}69760.3 \\
8 \\
\end{array}$ & $\begin{array}{c}2.00030000 \\
0 \\
\end{array}$ & $\begin{array}{c}5.2997000 \\
00\end{array}$ & $\begin{array}{c}163423.6 \\
3 \\
\end{array}$ & 69759.75 & 3.2747 & 0.6324 \\
\hline TSM & 163441. & 69736.7 & 2.00020000 & 5.2995333 & 163434.3 & 69741.49 & 7.3158 & -4.7240 \\
\hline
\end{tabular}


International Journal of Computer Science \& Engineering Survey (IJCSES) Vol.3, No.6, December 2012

\begin{tabular}{|c|c|c|c|c|c|c|c|c|}
\hline $89 / 5$ & 71 & 7 & 0 & 33 & 9 & & & \\
\hline $\begin{array}{l}\text { TSM } \\
89 / 6\end{array}$ & $\begin{array}{c}163422 . \\
05\end{array}$ & $\begin{array}{c}69652.3 \\
8\end{array}$ & $\begin{array}{c}2.00038333 \\
3\end{array}$ & $\begin{array}{c}5.2987333 \\
33\end{array}$ & $\begin{array}{c}163414.6 \\
5\end{array}$ & 69653.88 & 7.3988 & -1.4964 \\
\hline $\begin{array}{l}\text { GCGWP } \\
10 / 50,10\end{array}$ & $\begin{array}{c}163214 . \\
14\end{array}$ & $\begin{array}{c}69602.0 \\
8\end{array}$ & $\begin{array}{c}2.00221666 \\
7\end{array}$ & $\begin{array}{c}5.2982666 \\
67\end{array}$ & $\begin{array}{c}163217.2 \\
2\end{array}$ & 69602.77 & -3.0811 & -0.6863 \\
\hline $\begin{array}{l}\text { TSM } \\
89 / 4\end{array}$ & $\begin{array}{c}163523 . \\
83\end{array}$ & $\begin{array}{c}69785.1 \\
0\end{array}$ & $\begin{array}{c}1.99943333 \\
3\end{array}$ & $\begin{array}{c}5.2999166 \\
67\end{array}$ & $\begin{array}{c}163516.9 \\
6\end{array}$ & 69783.48 & 6.8741 & 1.6226 \\
\hline $\begin{array}{l}\text { GCG } \\
15 E / 35\end{array}$ & $\begin{array}{c}163359 . \\
15\end{array}$ & $\begin{array}{c}69712.5 \\
5\end{array}$ & $\begin{array}{c}2.00105000 \\
0\end{array}$ & $\begin{array}{c}5.2991666 \\
67\end{array}$ & $\begin{array}{c}163342.8 \\
6\end{array}$ & 69701.34 & 16.2915 & 11.2140 \\
\hline $\begin{array}{l}\text { DMP } \\
2007 / 12\end{array}$ & $\begin{array}{c}162971 . \\
34\end{array}$ & $\begin{array}{c}69675.3 \\
5\end{array}$ & $\begin{array}{c}2.00431666 \\
7\end{array}$ & $\begin{array}{c}5.2990000 \\
00\end{array}$ & $\begin{array}{c}162991.0 \\
7\end{array}$ & 69683.08 & -19.7340 & -7.7323 \\
\hline $\begin{array}{l}\text { WUC } \\
04 / 12\end{array}$ & $\begin{array}{c}163372 . \\
56\end{array}$ & $\begin{array}{c}69541.5 \\
7\end{array}$ & $\begin{array}{c}2.00076666 \\
7\end{array}$ & $\begin{array}{c}5.2977166 \\
67\end{array}$ & $\begin{array}{c}163373.3 \\
7\end{array}$ & 69542.53 & -0.8103 & -0.9593 \\
\hline
\end{tabular}

\section{CONCLUSIONS}

From the results it can be concluded that:

1. Regression models have been developed for predicting cartesian planimetric coordinates at different epochs in UMaT, Tarkwa campus using latitude and longitude at 95\% confidence level. But the validity of the model is limited to the range of parameters considered for this research.

2. The evening regression models are the best choice for predictions than the morning especially when predictable accuracy of the GPS observations is taken into consideration.

3. The results obtained from the model proved that the error associated in the prediction is much lower than the one obtained by the theoretical model.

4. Taking into account that a Handheld GPS was used for data collection, the accuracy of the developed model can be improved by using dual or single frequency GPS receivers mounted on a tripod, using differential GPS technique, accommodating more number of parameters and larger datasets beyond the study area to enable extrapolation as this model can only be used for interpolation purposes (within UMaT campus).

\section{ACKNOWLEDGMENTS}

The author is highly indebted to China University of Geosciences and University of Mines and Technology for their support.

\section{REFERENCES}

[1] Jekeli Christopher (2012), Geometric Reference Systems in Geodesy, Division of Geodetic Science, School of Earth Sciences Ohio State University, USA, 15pp.

[2]. Jijie Zhu (1994), "Conversion of Earth-Centered Earth-Fixed Coordinates to Geodetic Coordinates". IEEE Transactions on Aerospace and Electronic Systems, Vol. 30, No.3, pp 957-958.

[3]. Ralph M. Toms (1995), "An efficient algorithm for Geocentric to Geodetic coordinate conversion" $13^{\text {th }}$ Workshop on Interoperability of distributed simulations Orlando FL, September 18-22, pp1-2.

[4]. George P. Gerdan and Rodney E. Deakin (1999), "Transforming Cartesian Coordinates to Geographical Coordinates" The Australian Surveyor, Vol. 44, No.1, pp 55-59.

[5]. Robert Burtch (2006), "Comparison of the methods used in rectangular to geodetic coordinate transformation" ACSM Annual Conference and Technology Exhibition, Orlando, FL, April 21-16, pp 2-3. 
International Journal of Computer Science \& Engineering Survey (IJCSES) Vol.3, No.6, December 2012

[6]. Chanfang Shu, and Fei Li (2010), "An iterative algorithm to compute geodetic coordinates" Elsevier Computers \& Geosciences 36, pp1145-1149.

[7]. Gullu M., Yilmaz M., Yilmaz I. and Turgut B. (2011), "Datum Transformation by Artificial Neural Networks for Geographic Information Systems Applications" International Symposium on Environmental Protection and Planning: Geographic Information Systems and Remote Sensing Applications, 28-29 June, pp13-15.

[8]. Pinar Civicioglu (2011), "Transforming Geocentric Cartesian coordinates to geodetic coordinates by using differential search algorithm" Elsevier Computers \& Geosciences (2012), doi:10.1016/j.cageo.2011.12.011, pp1-2.

[9]. Soler, T., Han, J.Y. and Weston, N.D (2012), "Alternative transformation from Cartesian to Geodetic coordinate by least squares for GPS Georefencing Applications" Elsevier Computers and Geosciences 42, pp100-101.

[10]. Bernard Russel Bowring (1976), "Transformation from Spatial to Geographical Coordinates" Survey Review, Vol. XXIII, pp 323- 327.

[11]. Gregory J. Hoar (1982), Satellite Surveying Magnavox Advanced Products and Systems Company, 2829 Maricopa Street. Torrance, California 90503. 1982: pp 233 - 250.

[12]. Will Featherstone (1997), "A comparison of existing co-ordinate transformation model and parameters in Australia" Cartography, vol.26, No.1, pp 13-26.

[13]. Peter Vanícek (2000), An online Tutorial in Geodesy: Tutorial Notes, Academic Press, University of New Brunswick, Canada, pp 1-3.

[14]. Alfred Leick (2004), GPS Satellite Surveying $3^{\text {rd }}$ Edition. John Wiley \& Sons, Inc., Hoboken, New Jersey, USA, pp 35-36.

[15]. Marzooqi, Y. Al., Fashir, H. and Syed I. A. (2005), "Derivation of Datum Parameters for Dubai Emirates" FIG. Working Week, 2005 and GSDI-8, Cairo, Egypt. April 16-21, pp2-10.

[16]. Afram Dzidefo (2011), "Determination of transformation parameters between WGS84 and Ghana Geodetic Network": A Thesis submitted to the Department of Geomatic Engineering, Kwame Nkrumah University of Science and Technology, Kumasi, pp 22-23.

[17]. Seidu M. (2004), "GIS as a tool in water monitoring for Public Health and Safety Management" BSC Project Report, unpublished, University of Mines and Technology, Tarkwa, Ghana, 6 pp.

[18]. Kesse G.O. (1985), The mineral and Rock Resources of Ghana. Balkema Publishers. Rotterdam, 60 pp.

[19]. Yakubu Issaka and Bernard Kumi-Boateng (2011), "Control Position Fix using Single Frequency Global Positioning System Receiver Technique-A Case Study" Research Journal of Environmental and Earth Sciences 3(1): pp32-37.

[20]. Forson K. I. (2006), "Design of distribution network for University of Mines and Technology" BSc Project Report unpublished University of Mines and Technology, Tarkwa, Ghana, 2006: 5 pp.

[21]. Chris Rizos (1999), "Principles and Practice of GPS Surveying" Retrieved from: http://www.gmat.unsw.edu.au/snap/gps/gps_survey/chap5/521.htm (Accessed on 18 ${ }^{\text {th }}$ August, 2012).

[22]. Ahn Yong-Won (2012), GGE2012: Advance Surveying (Course work) University of New Brunswick, Canada, 2pp. 


\section{Authors}

Ziggah Yao Yevenyo is a Masters student in Geodesy and S u rve y Engineering at China University of Geosciences (Wuhan). Ziggah received his B.Sc. degree from University of Mines and Technology. Soon after, he worked as a Mining and Exploration Surveyor for Golden Star Resources (Bogoso/Prestea) and CBM Surveys Limited (2008-2010) where he supervised multiple projects in engineering and mining surveys. His current research interests are in reference frames, gravity field determination and geoid modeling.

Professor Youjian Hu is the Vice President, Faculty of Information Engineering. $\mathrm{He}$ is in the Department of Surveying and Mapping Engineering of China University of Geosciences. His current research interests are on quality control of CORS network, data processing algorithm, deformation monitoring and GPS CORS network for both large and local scale deformation monitoring and analysis.

Christian Odutola Amans is a Masters student in Geodesy and Surveying Engineering at China University of Geosciences (Wuhan). Chris received his Post Graduate Diploma (PGD) in Math and Statistics from Federal University of Technology, and a first Degree in Surveying and Geoinformatics in Akure, Nigeria. $\mathrm{He}$ is a surveyor to Terradix Geosolutions Ltd, Akure. His current research interests are reference frames, geographic information system and geoid modeling.

Dr. Bernard Kumi-Boateng is a senior lecturer and Head of Department of Geomatic Engineering, University of Mines and Technology (UMaT), Tarkwa, Ghana. He received his BSc. in Geomatic Engineering from UMaT, MSc. in Geoinformation Science from International Institute of Geo-information Science and Earth Observation, Netherlands and MSc. in Environmental System Management from Kwame Nkrumah University of Science and Technology (KNUST), Ghana and a $\mathrm{PhD}$ in Geomatic Engineering from UMaT. His research interests are in Land and Compensation Surveys, Geographic Information Systems, Remote Sensing, Digital Image Processing, and Carbon Sequestration.
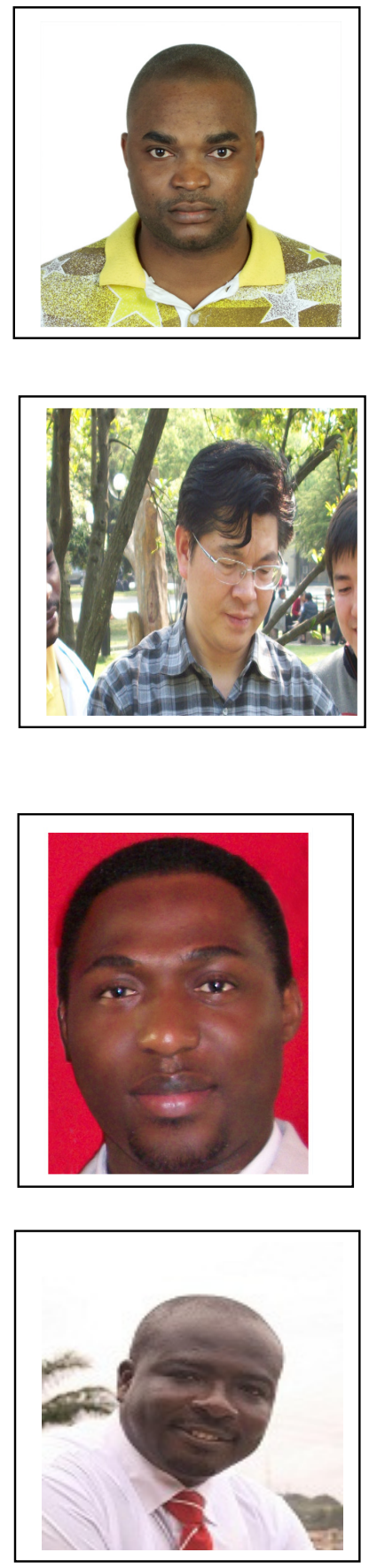